myokinase. A disadvantage of the method is the slow hydrolysis of adenosinetriphosphate in the final stages of the reaction.

2. Metallic salts of adenosinetriphosphate are shown to be unstable and break down on storage to adenylic acid and inorganic pyrophosphate, and to a less extent to adenosinediphosphate and inorganic phosphate.

3. The best preparations of adenosinetriphosphate are at least $95 \%$ pure. The possibility that some impurity is present is not excluded.
4. The use of potato apyrase for the assay of adenosinetriphosphate is restricted by its contamination with a nucleotidase and an inorganic pyrophosphatase.

5. Both in fresh and in rigor muscle, the adenosinediphosphate present is less than $5 \%$ and probably greater than $1 \%$ of the labile nucleotide phosphorus.

6. The claims of Banga concerning the action of muscle enzymes on adenosinetriphosphate are criticized.

\title{
REFERENCES
}

Albaum, G. H. \& Kletzkin, M. (1948). Arch. Biochem. 16, 333.

Bailey, K. (1942). Biochem. J. 36, 121.

Bailey, K. (1948a). Biochem. J. 42, lviii.

Bailey, K. (1948b). Nature, Lond., 160, 550.

Bailey, K. \& Webb, E. C. (1944). Biochem. J. 38, 294.

Bailey, K. \& Webb, E. C. (1948). Biochem. J. 42, 60.

Banga, I. (1947). Hungarica Acta Physiol. 1, 72.

Banga, I. \& Josepovits, G. (1947a). Hungarica Acta Physiol. 1, 67.

Banga, I. \& Josepovits, G. (1947b). Hungarica Acta Physiol. 1, 82.

Colowick, S. P. \& Kalckar, H. M. (1943). J. biol. Chem. $148,117$.

Fiske, C. H. (1934). Proc. nat. Acad. Sci., Wash., 20, 25.

Kalckar, H. M. (1943). J. biol. Chem. 148, 127.

Kalckar, H. M. (1944a). J. biol. Chem. 153, 355.
Kalckar, H. M. (1944b). J. biol. Chem. 154, 267, 275.

Kalckar, H. M. (1947). J. biol. Chem. 167, 445.

Kaplan, N. O. \& Neuberg, D. M. (1944). J. biol. Chem. 156, 511.

Kerr, S. E. (1941a). J. biol. Chem. 139, 121.

Kerr, S. E. (1941b). J. biol. Chem. 139, 131.

Kerr, S. E. \& Seraidarian, K. (1945). J. biol. Chem. 159, 637.

Kielly, W. W. \& Meyerhof, O. (1948). J. biol. Chem. 176, 591.

Kleinzeller, A. (1942). Biochem. J. 36, 729.

Krishnan, P. S. (1949). Arch. Biochem. 20, 261, 272.

Lohmann, K. (1928). Biochem. Z. 202, 466.

Lohmann, K. (1931). Biochem. Z. 233, 460.

Needham, D. M. (1942). Biochem. J. 36, 113.

Polis, D. B. \& Meyerhof, O. (1947). J. biol. Chem. 169, 389.

Rapoport, S. \& Nelson, N. (1945). J. biol. Chem. 161, 421.

\section{Preparation of the Antibiotic Nisin}

\author{
By N. J. BERRIDGE \\ National Institute for Research in Dairying, University of Reading
}

(Received 20 May 1940)

The early pharmacological work with nisin, prepared from Streptococcus lactis (Lancefield group N) (Mattick \& Hirsch, 1947) was remarkable for the success which attended the use of crude concentrates. Nevertheless, it was obvious that more potent material would be required for human therapy and for experiments with the less sensitive pathogens. A note (Berridge, 1947) added to the paper of Mattick \& Hirsch showed that highly active preparations in the form of crystals or tactoids could conveniently be made. The details of a number of such preparations are now described.

\section{METHODS}

(1) The unit of antibiotic activity. A preparation of nisin powder was chosen as a standard, and its activity defined as 1.3 units/ $\mu$ g.; 1 unit will normally just inhibit the growth of the test organism, Strep. agalactiae, in $1 \mathrm{ml}$. of broth (test Ai), and is roughly equal to the unit of Mattick \& Hirsch.

(2) Measurement of antibiotic activity. Three tests were given a prolonged trial during this work. A, Bacteriostatic tests: (i) dilutions of the antibiotic in powers of 2 in inoculated broth, with the recording of growth after $16 \mathrm{hr}$. and $40 \mathrm{hr}$. as,+++ or +++ ; (ii) dilution of the antibiotic in powers of 1.3-1.5 in broth or skim milk heavily seeded with sensitive acid-forming organisms with the recording of $\mathrm{pH}$ after 10-16 hr. incubation; and $B$, an apparently bactericidal test in which the proportion of organisms surviving a few minutes' contact with the antibiotic diluted in powers of 4 was determined by the plate count. It is quite possible that different activities were measured by the different methods. The details of the methods are as follows:

Method Ai. This did not differ significantly from that described by Mattick \& Hirsch (1947).

Method A ii. The nisin samples were diluted on the basis of an assumed activity to give solutions with about 10 units/ ml. Suitably spaced volumes (e.g. from $0.08 \mathrm{ml}$. increasing 
by powers of 1.5 to $1.20 \mathrm{ml}$.) were measured from a microburette into a series of sterile test tubes. For each set of determinations carried out on the same day with the same preparation of test organism, a standard nisin solution freshly diluted to 10 units $/ \mathrm{ml}$. was dispensed similarly but over a smaller range and at closer intervals (e.g. from $0.1 \mathrm{ml}$. rising by increments of $0.03 \mathrm{ml}$. to $0.70 \mathrm{ml}$.). Pasteurized skim milk tinted with litmus was inoculated with $1 \%(\mathrm{v} / \mathrm{v})$ of a $24( \pm 3) \mathrm{hr}$. culture of Strep. cremoris (strain 1P5) and $10 \mathrm{ml}$. mixed with the nisin solutions. The tubes were then incubated at $22^{\circ}$. The progressive reduction of the litmus by the growing micro-organisms, and the final clotting of the milk, enabled the state of each test to be observed at a glance. After about $10 \mathrm{hr}$. incubation $\mathrm{pH}$ determinations were made on each partly grown culture. From the graph of nisin concentration against $\mathrm{pH}$, drawn from the standard, it was then possible to determine the activity of the unknown solutions. If incubation was too prolonged the graph from the standard test became too steep, there being then only one or two intermediate points between which to draw the useful part of the curve. The same technique has been followed using yeastrel dextrose broth in place of milk. The heavy inoculum, and the rapid growth of the test organism at a comparatively low temperature, made it possible to dispense with most of the usual precautions of asepsis, but samples were freed from gross contamination by being diluted in $0.05 \mathrm{~N}-\mathrm{HCl}$.

The uncertainties in constructing and using the standard graphs gave an error of less than $\pm 10 \%$ in the final figures. The method was based on a suggestion of Hirsch, which he has since subjected to considerable study and elaborated into a 'lag-phase assay' (using Strep. agalactiae), the reproducibility of which has been statistically analysed (Hirsch, 1949).

Method B. A $0.001 \%$ suspension of a $24( \pm 3) \mathrm{hr}$. culture of Strep. agalactiae, giving a plate count of $3000-6000 / \mathrm{ml}$., was allowed to stand for $6 \mathrm{~min}$. in contact with serial dilutions of standard nisin diminishing from 50 units $/ \mathrm{ml}$. in powers of 2 , and of unknown solutions diminishing from about 100 units $/ \mathrm{ml}$. in powers of $4 ; 0.1 \mathrm{ml}$. of each mixture was then plated with $10 \mathrm{ml}$. of melted cooled agar and counts made after $24-48 \mathrm{hr}$. incubation at $37^{\circ}$. Reductions of $30-70 \%$ in the count usually occurred between 6 and 50 units $/ \mathrm{ml}$.

A rough graph was made by joining with straight lines the points obtained when $x$ was plotted against $y$, where $x=\log (100 a / b), a=$ number of organisms surviving contact with nisin, $b=$ number of living organisms before adding nisin, and $y=$ nisin concentration in contact with the organisms in the broth suspensions. The activities in the unknown solution were then obtained by interpolation. Although the variations from day to day were great, and although there were factors of unknown magnitude such as the number of organisms killed in, for example, tube no. 2 before transferring $1 \mathrm{ml}$. to tube no. 3, it was anticipated that they would be overcome by the preparing of a standard graph for each set of determinations. However, this was not so, for after a few months' trial the method appeared only a little better than method $\mathrm{Ai}$ and was therefore abandoned in favour of Ai for ordinary and Aii for special purposes, although by this time it had been used for most of the experiments in purifying and crystallizing nisin. The plate counts of Strep. agalactiae have shown a reproducibility unusual with long-chained organisms. This and other aspects of the 'bactericidal action' of nisin have been examined in detail by Hirsch (1949).
At an early stage of the work the use of Strep. cremoris in a test like $\mathrm{Ai}$ led to the preparation of a concentrate active against this organism but without effect upon Strep. agalactiae. Therefore test Aii with Strep. cremoris has been used only when its different sensitivity was not likely to be misleading.

(3) Determination of specific activity. Samples, usually of $0.1 \mathrm{ml}$., of nisin solutions were dried at $98-100^{\circ}$ in small platinum dishes, weighed on the microbalance, ashed, and reweighed as described elsewhere (Berridge, 1945). The

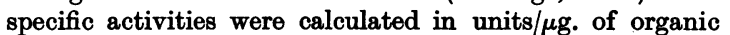
matter.

(4) Determination of nitrogen. The micro-Kjeldahl method of Tompkins \& Kirk (1942) was used but with the digestion mixture of Campbell \& Hanna (1937).

(5) Apparatus for cooling at a controlled rate. This was used for some of the later crystallizations.

A contact thermometer (electro-methods) in which the temperature setting could be controlled by rotating a magnet, was set up in a thermostatically controlled water bath. A train of Meccano gears and chain drives was then arranged between a synchronous electric motor and the controlling magnet so that the temperature of the water bath could be changed at any desired rate. The small fluctuation permitted by the contact thermometer appeared to be unimportant. With the help of a cooling coil connected to the main water supply, temperatures somewhat below room temperature could be reached.

(6) Diffusion measurements. Diffusion was allowed to take place through a sintered glass disk according to the technique described by Northrop \& Anson (1929) (see also Gordon, 1945). Special precautions were taken to overcome vibration, and the temperature was regulated at $25 \pm 0.003^{\circ}$. The vessel was standardized with $0 \cdot 1 \mathrm{~N}-\mathrm{KCl}$ using the value for the integral diffusion coefficient $D i=183.8 \times 10^{-7} \mathrm{~cm} .{ }^{2} /$ sec. (Gordon, 1945). Measurements with nisin were made by comparing the activities of the inner and outer solutions according to method Aii.

(7) Solubility determinations. The nisin suspensions were allowed to reach equilibrium in bottle-shaped vessels of about $0.5 \mathrm{ml}$. capacity, each containing a newly made glass bead of smooth bright surface, which stirred the suspension while the bottle was rotated in a vertical plane. The suspensions were transferred to the bottles with a Pasteur pipette having a waxed tip. By filling exactly to the neck it was possible to avoid bubbles and at the same time to achieve adequate stirring. In order to avoid a partial vacuum in the bottles after sealing, the necks were first pulled out to very fine tips, allowed to cool and finally sealed with a minute flame. The sealed bottles were packed in cotton wool and immersed in crushed ice in a quart Thermos flask which was rotated in a vertical plane. After equilibrium had been reached, the suspensions were allowed to settle for several days and the supernatant solutions removed by pipette. This process was repeated to ensure freedom from contamination by traces of solid, and the nitrogen content of the solutions determined.

\section{PREPARATIONS}

Preparation of crude concentrates. The nisin-producing organism was a Strep. lactis (Lancefield group N) strain M354/07, identical with that used by Mattick \& Hirsch (1947). It was propagated by daily subculturing in yeast dextrose lemco broth, in which medium nisin was also 
readily formed. Stock cultures were kept in bullock's heart medium in the refrigerator.

Concentrates were made by a method similar to that of Mattick \& Hirsch, viz. adsorption on to a $\mathrm{CHCl}_{3}$ emulsion followed by removal of the $\mathrm{CHCl}_{3}$. After growth the broth was acidified to $\mathrm{pH} 1 \cdot 9 \pm 0 \cdot 1$, allowed to stand for 1 or 2 days and siphoned off. The $\mathrm{pH}$ was raised to 5.0 and $3 \%$ (v/v) $\mathrm{CHCl}_{3}$ emulsified with the broth and kept suspended for about $30 \mathrm{~min}$. After $2 \mathrm{hr}$. settling the supernatant liquid was siphoned off. The residue was acidified with $0.12 \mathrm{ml}$. of $10 \mathrm{~N}-\mathrm{HCl} / \mathrm{l}$. of original broth, the $\mathrm{CHCl}_{3}$ distilled off in vacuo below $40^{\circ}$ and the remaining suspension filtered at pH 1.5 $\pm 0 \cdot 1$. The filtrate was boiled to destroy possible enzymes and concentrated fivefold in vacuo. An inactive precipitate was removed by raising the $\mathrm{pH}$ to $1 \cdot 9 \pm 0 \cdot 1$ and adding 2 vol. of ethanol and 1 of ether; the nisin itself was precipitated with a further 3 vol. of ethanol and 5 of ether and dried with ethanol and ether. Powders so prepared usually had specific activities of about 1 unit/ $\mu \mathrm{g}$.

Fractionation in phosphate buffer. It was found that a product of seven or eight times the specific activity of the crude material could be prepared by treatment with $\mathrm{M}-\mathrm{K}$ phosphate at $\mathrm{pH} 6 \cdot 1$, most of the activity remaining in the small insoluble portion. A solution of precipitate prepared in this way had a specific activity of 8 units/ $\mu \mathrm{g}$., and a dry powder with a specific activity of 8 units/ $\mu$ g. was obtained by precipitation with alcohol and ether.

The effect of $\mathrm{pH}$ on the fractionation was explored in an experiment in which $0.56 \mathrm{~g}$. of crude powder (kindly supplied by Benger's Ltd.) was suspended in $12 \mathrm{ml}$. $\mathrm{M}-\mathrm{H}_{3} \mathrm{PO}_{4}$, and precipitates were obtained and separated serially as the $\mathrm{pH}$ was raised from 1.4 through 2.3 and 3.8 to $>6$ and $<7$. After dissolving the precipitates in $0.05 \mathrm{~N}-\mathrm{HCl}$ their activities and organic dry weights were determined, giving the results shown in Table 1 , from which it is clear that fractionation at the lower $\mathrm{pH}$ values gives less increase in purity than was obtained in the previous experiments.

\section{Table 1. Fractionation in molar potassium phosphates at various $\mathrm{pH}$ values}

\begin{tabular}{|c|c|}
\hline $\begin{array}{c}\text { Total } \\
\text { activity } \\
\left(\text { units } \times 10^{6}\right)\end{array}$ & 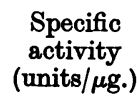 \\
\hline 0.6 & 1 \\
\hline
\end{tabular}

Original powder

Fraction:

(1) Precipitate_at pH 1.4!

(2) Precipitating between $\mathrm{pH} 1.4$ and 2.3

(3) Precipitating between pH 2.3 and 3.8

(4) Remaining soluble at $\mathrm{pH} 3.8$ to $>6$ and $<7$

Recovered in fractions

$\begin{array}{ll}0.6 & 3.4 \\ 0.2 & 3.8 \\ 0.1 & 1.9 \\ 0.08 & 0.2 \\ 0.98 & \end{array}$

The increase in total activity shown in Table 1 contradicted the first four experiments in which the yields appeared to be very low. The gains occurring in the following detailed example of the fractionation at $\mathrm{pH} 6 \cdot 1$ in $\mathrm{M}-\mathrm{K}$ phosphate were therefore determined as accurately as the method of activity measurement (b) wolld allow. Nisin powder (5.35 g., 0.9 unit/ $\mu \mathrm{g}$.) was dissolved in $106 \mathrm{ml}$. of $0.1 \mathrm{~N}-\mathrm{HCl}$ giving a turbid mixture of $\mathrm{pH} \mathbf{0 \cdot 9}$. The precipitate obtained on centrifuging dissolved readily in $0.05 \mathrm{~N}-\mathrm{HCl}$ and was added to the nisin residues. To the supernatant liquid sufficient $\mathrm{KH}_{2} \mathrm{PO}_{4}$ was added to bring the concentration to molar, i.e. $14 \mathrm{~g}$., and after solution, the $\mathrm{pH}$ was raised to 6.11 with concentrated $\mathrm{KOH}$ (about $10 \mathrm{ml}$.). The precipitate, which began to form before the $\mathrm{pH}$ reached 3 , increased until about pH 5, and decreased again greatly by pH 6. That which remained was allowed to stand until well flocculated, but even so the supernatant liquid obtained by centrifuging was not clear. A clear supernatant was produced, however, by a second centrifuging after the liquid had been allowed to stand overnight in the refrigerator. Thus a main and a subsidiary precipitate were obtained. The main precipitate was dissolved in $30 \mathrm{ml}$. of distilled water and adjusted with $\mathrm{HCl}$ to a final $\mathrm{pH}$ of 1.9 . The solution had an activity of 250,000 units $/ \mathrm{ml}$. The total activities existing at the various stages are recorded in Table 2.

\section{Table 2. Increases in activity during fractionation} in phosphate buffer

Total activity (units $\times 10^{6}$ )

Starting material (5.35 g. at 0.9 unit/ $\mu \mathrm{g}$.)

Solution in $0.1 \mathrm{~N}-\mathrm{HCl}$ (A)

Precipitate from $0 \cdot 1 \mathrm{~N}-\mathrm{HCl}$

- 4.8

$4 \cdot 6$
$1 \cdot 6$ $6 \cdot 2$

Solution (A) after adding phosphate and adjusting to pH 6.1 (sample 'activated' by standing overnight in $100 \mathrm{ml} .0 .05 \mathrm{~N}$ HCl)

Solution of main precipitate

Solution of subsidiary precipitate

Supernatant buffer solution (after acid

- 5.5

'activation' as above)

In this experiment, therefore, $7.8 \times 10^{6}$ units, with a specific activity of presumably about 8 units/ $\mu$ g., were prepared from $4.8 \times 10^{6}$ units, with a specific activity of $0.9 \mathrm{unit} / \mu \mathrm{g}$. This apparent increase has been confirmed but not further investigated.

Further purification by fractional precipitation with sodium chloride. An exploratory fractionation of the solution from the above experiment was made by dissolving in it gradually increasing quantities of $\mathrm{NaCl}$, centrifuging as soon as a fifth to a tenth of the nisin appeared to be precipitated, and repeating the process until no further precipitate appeared. In this way five roughly equal fractions were obtained. Their specific activities were respectively $20,18,27,24$ and $5 \cdot 0$ units/ $\mu$ g. There seemed to be a loss of about $50 \%$, but the activities of some of the acid solutions of the precipitates increased on keeping. Attempts to purify these fractions further by other methods, which are described below, were unsuccessful. Purification was therefore again attempted with fresh material.

Crude nisin powder was fractionated with phosphate buffer as already described, giving a solution of purified nisin in dilute $\mathrm{HCl}$ at $\mathrm{pH} 2$. A slight precipitate produced by adding $\mathrm{NaCl}$ was discarded, and the bulk of the nisin then precipitated by saturation with $\mathrm{NaCl}$ and redissolved at $\mathrm{pH} 1.8$. From 10 million units of crude nisin $130 \mathrm{ml}$. of purified solution containing 17 million units were obtained, an increase as before. Seven portions of $\mathrm{NaCl}$ were added in turn to this solution, the precipitate salted out by each being collected for the determination of total and specific activity. The procedure and results are summarized in Table 3. The final solution at $\mathrm{pH} 1 \cdot 0$ contained an insignifi. cant quantity of nisin. 
Table 3. Fractionation of nisin solutions by precipitation with sodium chloride

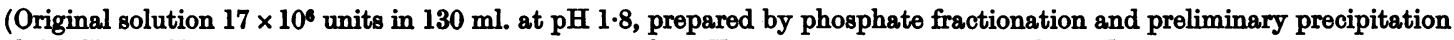
with $\mathrm{NaCl}$. $\mathrm{NaCl}$ ( $x$ g.) was added to supernatant number $(Y)$ to give precipitate number $(Y+1)$.)

$\begin{array}{ccc}\begin{array}{c}\text { Supernatant } \\ \text { number } \\ (Y)\end{array} & \begin{array}{c}\text { NaCl } \\ \text { added } \\ (x \text { g. })\end{array} & \begin{array}{c}\text { Precipitate } \\ \text { number } \\ (Y+1)\end{array} \\ 0 & \mathbf{4 . 5} & 1 \\ 1 & 1 & 2 \\ 2 & 1 & 3 \\ 3 & 1 \cdot 5 & 4 \\ 4 & \mathbf{3} & 5 \\ \mathbf{5} & \mathbf{4 . 5} & 6 \\ \mathbf{6} & \mathbf{1 5} & \mathbf{7} \\ \mathbf{7} & - & -\end{array}$

Thus, considerable increases in specific activity could be achieved by fractionation with $\mathrm{NaCl}$.

Crystallization. Precipitates 2, 3 and 4 (selected before the specific activities had been determined) were united (20 ml. in all), adjusted to $\mathrm{pH} 2$ and the solution saturated with $\mathrm{NaCl}$. The resulting precipitate was washed with $3 \mathrm{ml}$. of distilled water, and then extracted three times with distilled water containing sufficient $\mathrm{NaOH}$ to give, in the mixture, a $\mathrm{pH}$ of 6.2, as described for extractions at $\mathrm{pH} 5 \cdot 6$ under 'Other methods of concentration and fractionation' (p.491). Numerous attempts were made to crystallize these extracts by various techniques, especially by several different ways of slowly adding $\mathrm{NaCl}$. The precipitates obtained were always granular and amorphous, but occasionally they contained a minute proportion of straight needles. The third of the extracts had been precipitated with $\mathrm{NaCl}$ several times at pH 2 when crystallization from ethanol was attempted. An equal volume of absolute ethanol was added to the centrifuged precipitate causing its immediate solution, followed by a slower precipitation which was reversible and dependent on temperature. On cooling the solution gradually from 37 to $0^{\circ}$ a semi-solid suspension of long thin needles was formed. This was filtered in the refrigerator through a small disk of filter paper (about $1 \mathrm{~cm}$. diam.), washed with a little ice-cold $80 \%(\mathrm{v} / \mathrm{v})$ ethanol, and dissolved in $1 \mathrm{ml}$. of $0.05 \mathrm{~N}-\mathrm{HCl}$. Triplicate determinations of the organic dry weight of this solution gave $0.65,0.61$ and $0.63 \mathrm{mg} . / 0.1 \mathrm{ml}$. The activity was 4600 units $/ 0.1 \mathrm{ml}$. Thus the specific activity of the crystals or tactoids was 73 units/ $\mu \mathrm{g}$.

Further preparations of 'crystalline' nisin. Comparatively large quantities of 'crystalline' nisin were needed for animal experiments, and a series of eight preparations were next made from dry powders at 10 units/ $\mu \mathrm{g}$., which were now being produced by a small pilot plant.

The preparations were made according to modifications of the method described under 'Final preparation' (p. 490). In the first four of them particular attention was paid to the effect of various modifications on the yield. These yields, based not on weight but on activities, were respectively $24,15,26$ and $15 \%$ of the starting material, but to avoid prolixity the experience of the whole series of preparations is summarized in the following points:

(1) It was thought that previous failures to crystallize from aqueous media might have been due to impurities which ethanol crystallization would remove, but the 'crystalline' substance, transferred to $0.05 \mathrm{~N}-\mathrm{HCl}$ and salted out with 0.25 saturated $\mathrm{MgSO}_{4}$ solution reappeared in

\begin{tabular}{|c|c|c|}
\hline \multicolumn{3}{|c|}{ Resuspended precipitate $(Y+1)$} \\
\hline 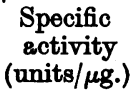 & $\begin{array}{c}\text { Total } \\
\text { activity } \\
\left.\text { (units } \times 10^{6}\right)\end{array}$ & pH \\
\hline 20 & - & $2 \cdot 3$ \\
\hline 30 & $2 \cdot 9$ & - \\
\hline 23 & $1 \cdot 7$ & 2.5 \\
\hline 31 & 1.4 & - \\
\hline 34 & $2 \cdot \overline{6}$ & $2 \cdot 6$ \\
\hline 17 & $1 \cdot 0$ & - \\
\hline 16 & 0.9 & $2 \cdot 8$ \\
\hline - & 一 & $1 \cdot 0$ \\
\hline
\end{tabular}

the amorphous condition, although the $\mathrm{MgSO}_{4}$ was added so slowly that 6 days were required for the precipitation.

(2) Most of the preparations contained a small quantity of gummy substance which would not dissolve in $80 \%$ ethanol but which could be removed by filtration at $37^{\circ}$, a process requiring about $24 \mathrm{hr}$. An attempt to increase the yield by increasing the middle fraction at the expense of both of the others led to such an increase in the quantity of the gummy substance that filtration was practically impossible. However, repeated extraction with $80 \%$ ethanol at $37^{\circ}$ by centrifuging gave clear liquids which 'crystallized' well, but the yield was low.

(3) The separation of too little of the least soluble fraction led to a middle fraction which remained amorphous indefinitely during repeated 'recrystallizations'.

(4) Considerable quantities of nisin could be recovered from abortive experiments, and from mother liquors and other ethanolic residues by diluting with 5 vol. of distilled water, precipitating by saturation with $\mathrm{NaCl}$ and fractionating according to the simple unmodified scheme.

(5) Unless the properties of the starting material rendered the least soluble fraction inordinately large its further fractionation was uneconomic. 'Working up' processes of varying complexity, but always on the lines of the main preparation, were tried out on the least soluble fractions of three preparations. From only one was a significant increase in yield obtained.

(6) Nisin can be precipitated from dilute solution in $80 \%$ ethanol by raising the apparent $\mathrm{pH}$ to about 6 , but whenever this was done there were great losses in activity.

(7) The correct acidity is essential for the formation of regular needles. Different quantities of $\mathrm{HCl}$ and $\mathrm{NH}_{3}$ were added to samples of a suspension which had precipitated in the usual form of very long thin needles. The less acid suspensions needed considerable dilution before they could be brought into solution. After warming to dissolve and cooling slowly the precipitates were in the form of irregular thin crumpled plates from solutions of $\mathrm{pH} 2.42,2.74$ and 3.60 , and microscopic needles at $\mathrm{pH} 4.22$ diminishing again to microscopic threads at $\mathrm{pH} 4 \cdot \mathbf{7 4}$.

These observations suggest that the losses sometimes experienced as a result of difficulty in redissolving the needles in $80 \%(v / v)$ ethanol could have been avoided by using acidified ethanol and adjusting the $\mathrm{pH}$ after solution.

(8) The size of the needles could be considerably increased at the optimum acidity by controlling the rate of cooling. All arrangements of lagged vessels involve, at the 
beginning of the process, a comparatively rapid cooling which leads to the formation of numerous small particles. With the apparatus already described (see Methods) this effect may be avoided without unduly prolonging the period of cooling. When cooled at the rate of $0.5^{\circ} / \mathrm{hr}$. a sample which had previously given 'crystals' appearing under the microscope ( $\frac{3}{4}$ in. objective) as fine needles now formed a precipitate recognizable as needles with some difficulty by the naked eye, but with ease at a magnification of 10 diameters.

(9) Several other methods of crystallization were tried without success, such as, for example, allowing an aqueous solution to evaporate in a desiccator at atmospheric pressure, removing water from a solution in $80 \%(v / v)$ ethanol by keeping in a desiccator over $\mathrm{Ca}$ metal (nisin is soluble in $80 \%$ but not in absolute ethanol), and stirring an acid ethanolic solution in a desiccator over dilute ammonia.

Final preparation. Nisin powder, $17 \cdot 4$ g. at 10 units/ $\mu$ g., was suspended in $700 \mathrm{ml}$. of distilled water by gentle stirring during about $30 \mathrm{~min}$. The addition of $3 \mathrm{ml}$. of concentrated $\mathrm{HCl}(36 \% \mathrm{w} / \mathrm{v})$ brought all but traces of the nisin into solution to produce a brown turbid liquid. After its $\mathrm{pH}$ had been brought up to 1.8 with a little $15 \%(w / v)$ ammonia, $28 \mathrm{~g}$. $\mathrm{NaCl}$ were dissolved in the nisin solution and the resulting dark brown gelatinous precipitate filtered off immediately with Whatman no. 54 paper. Notwithstanding the increasing opalescence of the filtrate resulting from equilibrium not having been established, a further $4 \cdot 4 \mathrm{~g}$. $\mathrm{NaCl} / 100 \mathrm{ml}$., actually $29 \mathrm{~g}$. in $650 \mathrm{ml}$., were added. The precipitate which now formed was stirred in its mother liquor for about $30 \mathrm{~min}$. before being filtered off (again no. 54 paper; both these filtrations were very rapid). The creamcoloured semi-solid precipitate was easily removed from the paper and was resuspended in enough distilled water to give a volume of $360 \mathrm{ml}$., in which it dissolved slowly. One half volume of saturated $\mathrm{NaCl}$ solution was now added slowly with continual stirring. By repeated gentle centrifuging the resulting precipitate was easily consolidated in one tube where it was dissolved by warming and shaking with about 1.2 vol. of absolute ethanol to give $150 \mathrm{ml}$. of clear brown solution. The ' $\mathrm{pH}$ ' (' $\mathrm{pH}$ '= Glass electrode reading of $0.1 \mathrm{ml}$. ethanolic solution $+1 \cdot 1 \mathrm{ml}$. distilled water) of this solution was raised with dilute ammonia from $3 \cdot 5$ to $4 \cdot 21$, a procedure which diminished the solubility of the nisin so that it was now necessary to warm it to $45^{\circ}$ before complete solution occurred. On cooling from this temperature at the rate of $1 \% / \mathrm{hr}$. without stirring, comparatively large needles were formed. The brown colour remained in the mother

Table 4. Purification of nisin

Procedure

$17 \cdot 4 \mathrm{~g}$. powder in $700 \mathrm{ml} .+28 \mathrm{~g} . \mathrm{NaCl}$

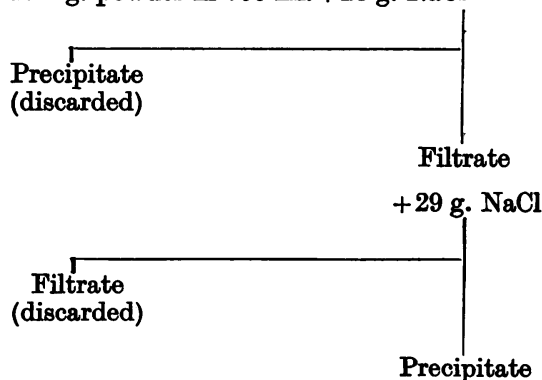

Quantity

(units $\times 10^{7}$ )

21

17

12

Dissolved in water to $360 \mathrm{ml}$. $+180 \mathrm{ml}$. saturated $\mathrm{NaCl}$ solution. Centrifuged

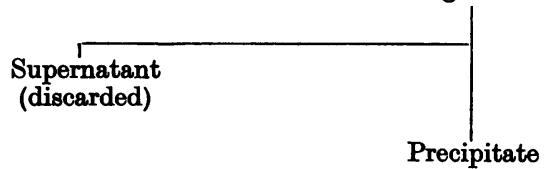

Dissolved in ethanol to $180 \mathrm{ml}$ at $45^{\circ}$ and ' $\mathrm{pH}$ ' $4 \cdot 2$. Cooled at $1 \% \mathrm{hr}$. Centrifuged
Mother liquor (to residues)

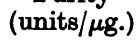

12

Redissolved in $80 \%(v / v)$ ethanol at $37^{\circ}$ and 'pH' $4 \cdot 2$. Filtered at $37^{\circ}$ and recrystallized by slow cooling 
liquor. On resuspending the precipitate in $80 \%(w / v)$ ethanol a mixture of ' $\mathrm{pH}$ ' 4.7 was obtained and some difficulty was encountered in achieving complete solution even at ' $\mathrm{pH}$ ' 4.2. Although $80 \%$ (w/v) ethanol was added until the volume of suspension was $280-300 \mathrm{ml}$. some insoluble particles indistinguishable from the needles remained. (Probably better results would have been obtained by dissolving the precipitate at ' $\mathrm{pH}$ ' $3 \cdot 0-3.5$ in a volume equal to that of the mother liquor and raising the ' $\mathrm{pH}$ ' to 4.2.) The dilute solution was filtered overnight at $37^{\circ}$ before sampling for yield and purity. On cooling at $0.5^{\circ} / \mathrm{hr}$. it gave needles similar to the former ones but practically white in colour. They were smaller than those mentioned in (8) above. The process is summarized in Table 4. At this early stage it cannot be stated whether the discrepancy between the specific activity of this material and that of the 'crystals' first obtained arose from errors in the measurements of activity, from errors in standardization, or from actual differences in composition.

Other methods of concentration and fractionation. At $\mathrm{pH}$ values near neutrality crude nisin was adsorbed from the broth in which it had been produced on to each of all the insoluble substances tested, e.g. aluminium hydroxide, charcoal of all grades, benzoic acid (pH 3-4), emulsified ether, ethyl acetate, $\mathrm{CHCl}_{3}, \mathrm{CCl}_{4}$, trichloroethylene and cellulose (filter-paper pulp). It was always difficult to recover the nisin from the adsorption complex. Occasionally, as with cellulose, it could be obtained by extraction at pH $1 \cdot 8$, but even so the losses were high.

From solution at about 1000 units $/ \mathrm{ml}$. nisin was readily precipitated by a variety of protein-precipitating reagents such as tannic acid, phosphotungstic acid and uranyl acetate, but again the difficulty was the recovery of the material in an active condition.

Further fractionation of the concentrated, partly purified material $(200,000$ units/ml., 8 units/ $\mu$ g.) by partial precipitation of an ethanolic solution with ether gave some promise of success, but was eventually abandoned as unattractive.

Repeated extraction of precipitated nisin at pH $5 \cdot 6$ with distilled water gives results similar, but perhaps inferior, to those from partial precipitation with $\mathrm{NaCl}$. In a preliminary experiment beginning with a preparation at 8 units/ $\mu \mathrm{g}$. it was possible to account for roughly $50 \%$ of the activity, while the last extract had a specific activity of $27 \mathrm{units} / \mu \mathrm{g}$. A second experiment was made in which $4.4 \mathrm{~g}$. of powder at 1 unit $/ \mu \mathrm{g}$. were subjected to fractionation in phosphate buffer (see p. 488), the nisin being precipitated from the final solution at $\mathrm{pH} 1.7$ by saturation with $\mathrm{NaCl}$. The precipitate was extracted by 'creaming' it with distilled water, diluting to about $20 \mathrm{ml}$. with distilled water, adjusting its pH to $5 \cdot 5-5 \cdot 7$, and centrifuging. The procedure was repeated twice, using the remaining residue each time. Three extracts and one residue were thus obtained. The first extract only was further purified by centrifuging away the first turbidity which appeared when $\mathrm{NaCl}$ was added very gradually, precipitating the remaining nisin by saturation with $\mathrm{NaCl}$, and extracting this precipitate once with distilled water at $\mathrm{pH} 5 \cdot 5$. All solutions were now precipitated by saturating with $\mathrm{NaCl}$ and centrifuged. These and the other precipitates were finally dissolved in $2-5 \mathrm{ml} .0 .05 \mathrm{~N}-\mathrm{HCl}$ before testing their activities. The results are shown in Table 5. Neither these nor those of Table 3 are adequate for a comparison of the methods, because the differences are not great. In the absence of further evidence fractionation with $\mathrm{NaCl}$ is, however, to be preferred on account of the greater stability of nisin at the lower $\mathrm{pH}$ values there employed.

\section{Table 5. Fractionation of nisin at $\mathrm{pH} \mathbf{5 \cdot 6}$}

$\begin{array}{llc}\text { Original powder } & 4 \cdot 4 & 1.0 \\ \begin{array}{l}\text { Fractions: } \\ \text { Phosphate fraction }\end{array} & - & 8^{*} \\ \text { First extract: } & 0 \cdot 07 & - \\ \quad \text { First turbidity with NaCl } & 0 \cdot 22 & 7 \cdot 7 \\ \text { Extract at pH 5.5 } & 0 \cdot 26 & - \\ \text { Precipitate at pH 5.5 } & 1 \cdot 4 & 23 \\ \text { Second extract } & 0 \cdot 79 & 23 \\ \text { Third extract } & 0 \cdot 71 & - \\ \text { Residue } & 3.45 & \\ \quad \text { Total recovery } & \end{array}$

* Assumed on the basis of other experiments.

\section{PROPERTIES OF NISIN}

The biological properties of crude nisin preparations have already been described (Mattick \& Hirsch, 1947; Hirsch, 1949).

Stability. Dry nisin powder appears to keep indefinitely in an ordinary atmosphere. At pH 6.8 and $37^{\circ}$ in dextrose lemco broth nisin retains its activity for at least $24 \mathrm{hr}$.; solutions at $\mathrm{pH} 1.8$ are stable for weeks. Boiling at $\mathrm{pH} \mathrm{1.8-}$ 2.0 for 5-10 min. tends, if anything, to increase slightly the activity of dilute nisin solutions. Moreover, concentrated solutions prepared by dissolving 'crystals' from ethanolic solution in dilute $\mathrm{HCl}$ and adjusting to $\mathrm{pH} 2.0$ may be boiled in an open beaker until free from ethanol without appreciable loss of activity, and saturated solutions at pH 4.2 may be 'sterilized' for injection by boiling for $10 \mathrm{~min}$. Autoclaving, however (10 lb./sq.in. for $10 \mathrm{~min}$.), destroys about $50 \%$ of the activity. In boiling $2 \mathrm{~N}-\mathrm{HCl}$ destruction is complete after $2 \mathrm{~min}$. In alkaline solutions the activity is quickly destroyed. An acid solution was immediately inactivated by potassium permanganate but not by sodium sulphide.

Nisin was suspected to be a peptone. It appeared possible therefore that it would be rapidly destroyed in an enzymerich medium such as blood. Preliminary experiments showed that nisin could be assayed in blood using method Ai with an inoculum of $1 \%$ of a $24 \mathrm{hr}$. culture of Strep. agalactiae. Method B could also be used. It was then demonstrated by the former method that 6000 units $/ \mathrm{ml}$. in blood at $37^{\circ}$ remained undiminished for at least $22 \mathrm{hr}$. Method B was then used to demonstrate an equal stability of nisin under similar conditions at a level of 15 units $/ \mathbf{m l}$. Fresh citrated whole blood was used.

Solubility. (i) In blood. As nisin was known to have a comparatively low solubility at $\mathrm{pH}$ levels near neutrality its solubility in blood became of interest as a factor which might limit its therapeutic use. After the preliminary tests described above, method B was used to measure, first, the distribution between corpuscles and plasma and, secondly, the activity of plasma after adding various quantities of nisin to blood and centrifuging. It was found that the nisin was distributed evenly between the plasma and the corpuscles, medium concentrations remaining unaffected by 
centrifuging, and that the 'solubility' in blood is not less than 5000 units $/ \mathrm{ml}$., a value not too low to prevent its therapeutic use.

(ii) In water. At low $\mathrm{pH}$ values nisin is very soluble. At a pH about $4 \cdot 2$ saturated solutions of 'crystalline' nisin had an activity of 600,000 units $/ \mathrm{ml}$., corresponding to a solubility of approximately $1.5 \%(w / v)$. In extraction experiments nisin at about 20 units/ $\mu$ g. gave solutions containing 40,000 units $/ \mathrm{ml}$. at $\mathrm{pH} 5 \cdot 6$, but here adsorption effects may have interfered.

(iii) In organic solvents. Preliminary qualitative tests indicated that those compounds which dissolved nisin usually destroyed its activity, e.g. glacial acetic acid, benzyl alcohol. Ethanol $(80 \% \mathrm{w} / \mathrm{v})$ and formamide were exceptions, in that full activity was retained.

Molecular size. A rough measurement of the diffusion coefficient of nisin was made using the sintered disk method. This method was chosen because the results can be obtained from activity determinations alone, inactive impurities causing only indirect effects, such as, for example, the possible effect of rapidly diffusing molecules on the viscosity of the liquid into which a slower molecule might diffuse. It was, furthermore, impossible to find laboratory accommodation free from vibration. The details of the arrangement employed are described under Methods (p.487).

A preliminary single determination of the diffusion coefficient gave $15 \times 10^{-7} \mathrm{~cm} .^{2} / \mathrm{sec}$. In the next experiment diffusion was allowed to proceed for a total of $45 \cdot 7 \mathrm{hr}$., the outer liquid being renewed at intervals. It is probable that the differences which still appeared (see Table 6) after equilibrium should have been established were due to uncertainties in the biological assay. Thus the value of $14 \times 10^{-7} \mathrm{~cm} .{ }^{2} / \mathrm{sec}$. for the diffusion coefficient of nisin is merely approximate. Nevertheless, it serves to show that nisin is probably a small protein or large polypeptide molecule (cf. $D$ (diffusion coefficient at infinite dilution) $=10.57 \times 10^{-7}$ for lactalbumin, $10.11 \times 10^{-7}$ for cytochromec: Polson, 1939; Schmidt, 1943). cipitated from ethanolic solution, was dissolved in $0.05 \mathrm{~N}-\mathrm{HCl}$ and salted out by the slow addition of $\mathrm{NaCl}$ through a rotating membrane (McMeekin, 1939). The resulting granular precipitates were convenient for settling, filtering and washing. The material for the first experiment was equilibrated with buffer by five washings on a sintered glass filter, that for the second by dialysis with renewal of buffer daily for 13 days. After this second procedure, $25 \%$ of the nisin was discovered to be insoluble; probably chemicals from the insufficiently washed collodion membrane brought

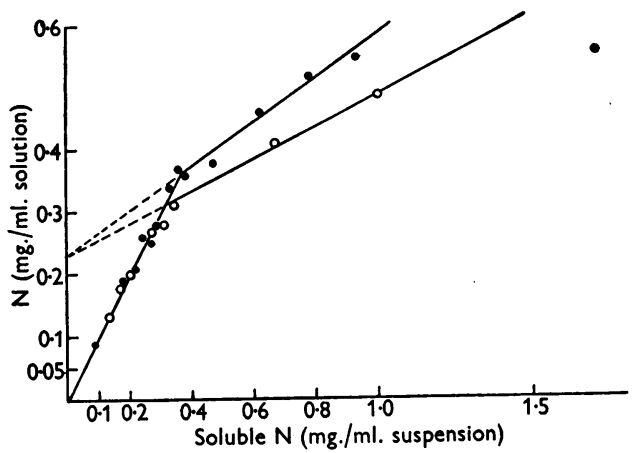

Fig. 1. Solubility of nisin: O, Exp. 1; O, Exp. 2.

about denaturation; $25 \%$ was therefore subtracted from the figures for total $\mathrm{N}$ in the second solubility experiment. The buffer was made by dissolving $26 \mathrm{~g}$. $\mathrm{KH}_{2} \mathrm{PO}_{4}$ and $60 \mathrm{~g}$. $\mathrm{KCl}$ in $800 \mathrm{ml}$. of distilled water, adding $10 \mathrm{~N}-\mathrm{HCl}$ to $\mathrm{pH} 1.92$ and finally making up to $1 \mathrm{l}$. Nisin suspensions of different concentrations were made, and after equilibrium had been established the solutions were separated and analysed for nitrogen as already described (see p. 487). Both sets of results are shown graphically in Fig. 1, from which it is clear that these preparations contained at least two components,

Table 6. Diffusion of nisin

(Inner solution; nisin, $65 \mathrm{ml}$. at $\mathbf{1 7 5 , 0 0 0}$ units/ml. Outer solution; solvent, $25-50 \mathrm{ml}$.)

$\begin{array}{ccc}\text { Time during } & \\ \text { Diffusion } & \begin{array}{c}\text { which diffusion } \\ \text { occurred } \\ \text { no. }\end{array} & \begin{array}{c}\text { Units } \\ \text { diffused }\end{array} \\ \text { 1 } & 4 \cdot 5 & 81,000 \\ 2 & 17 \cdot 1 & 94,000 \\ 3 & 12 \cdot 0 & 80,000 \\ 4 & 12 \cdot 1 & 85,000\end{array}$

Amino-acid composition. Paper partition chromatography (Consden, Gordon \& Martin, 1944) was used to analyse a hydrolysate of 'crystalline' nisin. The following amino-acids were recognized; alanine, valine, leucine, isoleucine. Cystine and aspartic acid were possibly present. There were also several faint or unrecognizable spots.

Purity. The solubility of nisin depends on the quantity of solid phase present; when the concentration of the solution was plotted against that of the suspension two straight lines of different slope were obtained showing that the preparation contained at least two components. A solution saturated with respect to all components was not obtained.

Two main experiments were carried out. For each of them a different preparation of nisin, in the form of needles pre-

\begin{tabular}{|c|c|}
\hline $\begin{array}{c}\text { Units } \\
\text { diffused/hr. }\end{array}$ & $\begin{array}{l}\text { Diffusion } \\
\text { coefficient } \\
\text { (cm. }{ }^{2} / \text { sec. }^{-}\end{array}$ \\
\hline $\left.\begin{array}{r}18,000 \\
5,500 \\
6,700 \\
7,000\end{array}\right\}$ Mean 6,400 & $\begin{array}{c}- \\
14 \times 10^{-7}\end{array}$ \\
\hline
\end{tabular}

the less soluble of which amounted to about two-thirds of the total mixture. The possibility mentioned by Butler (1941) that different forms of one component may persist although not in equilibrium, remains to be examined, but it seems remote because of the slow precipitation of the solid used in these experiments.

\section{DISCUSSION}

Throughout the work there were a number of unexplained observations which could not then be further investigated. The increases in activity recorded in Tables 1 and 2 are among them. Some 
of the others may be merely mentioned, for example: $(a)$ the activity of acidified broth containing nisin was destroyed on attempting to concentrate in vacuo, some activity reappearing on keeping; (b) when the organism was allowed to grow at $22^{\circ}$ instead of $30^{\circ}$ a concentrated product active against Strep. cremoris but not against Strep. agalactiae was obtained; $(c)$ significant yields were obtained in some media after steaming, but not after autoclaving, although the organisms still grew well; and $(d)$ the sensitivity of nisin to certain chemicals and solvents contrasts strangely with its stability to others and to acids and heat.

It was impossible to prove that the needles observed were true crystals. Their shape in cross-section could not be observed. The slow filtering and the slightly syrupy nature of the ethanolic solutions, as well as the formation of gels when such solutions were rapidly cooled, suggests that the needles may well have been tactoids.

Although a few preliminary experiments have shown that nisin is closely associated with a polypeptide, the solubility measurements indicate that further purification is required before the properties of the active substance, or substances, can be properly investigated. Meanwhile, the purification so far achieved has facilitated experiments in other directions.

\section{SUMMARY}

1. Experiments in concentrating and purifying the antibiotic nisin are described.

2. Nisin may be obtained in the form of needles by cooling a solution in $80 \%$ ethanol at ' $\mathrm{pH}$ ' 4.2 (' $\mathrm{pH}$ ' is glass electrode reading of ethanolic solution diluted with 11 volumes distilled water).

3. The properties of the 'crystalline' product have been investigated. It will inhibit the growth of the more sensitive organisms at dilutions from $10^{-8}$ (Strep. agalactiae) to $10^{-9}$ (Strep. cremoris); it is stable for weeks in acid solution and for many hours in blood at $37^{\circ}$; it contains the amino-acids alanine, valine, leucine, isoleucine and others, and appears to consist of a mixture of at least two polypeptides.

Special thanks are due to Benger's Ltd. (of British Chemicals and Biologicals Ltd.) for their co-operation in making, and generosity in supplying, active concentrates. The helpful encouragement given by the Director, Prof. H. D. Kay, and the invaluable support of the AssistantDirector, Dr A. T. R. Mattick, are gratefully acknowledged. Thanks are also expressed to Dr A. Hirsch for useful suggestions. The work described under 'Preparation of crude concentrates' was carried out in the laboratories of Benger's Ltd., whose Director, Mr B. D. Thornley, is to be thanked, as are also Dr E. G. Stopher, Mr C. Epstein, and Miss E. M. Barnes, members of the staff, for their assistance. The later help of Mrs C. Waterhouse is acknowledged with thanks.

\title{
REFERENCES
}

Berridge, N. J. (1945). Biochem. J. 39, 179.

Berridge, N. J. (1947). Lancet, ii, 5.

Butler, J. A. V. (1941). J. gen. Physiol. 24, 189.

Campbell, W. R. \& Hanna, M. J. (1937). J. biol. Chem. 119, 1 .

Consden, R., Gordon, A. H. \& Martin, A. J. P. (1944). Biochem. J. 38, 224.

Gordon, A. R. (1945). Ann. N.Y. Acad. Sci. 46, 285.

Hirsch, A. (1949). J. gen. Microbiol. (in the Press).

Mattick, A. T. R. \& Hirsch, A. (1947). Lancet, ii, 5.
McMeekin, T. L. (1939). J. Amer. chem. Soc. 61, 2884.

Northrop, J. H. \& Anson, M. L. (1929). J. gen. Physiol. 12, 543.

Polson, A. (1939). Kolloidzschr. 87, 149.

Schmidt, C. L. A. (1943). Addendum to the Chemistry of the Amino Acids and Proteins, p. 1119. Baltimore: Charles C. Thomas.

Tompkins, E. R. \& Kirk, P. L. (1942). J. biol. Chem. 142, 477.

\section{The Cholinesterase Activity of the Serum of Newborn Animals, and of Colostrum}

\author{
By R. A. McCANCE, A. O. HUTCHINSON, R. F. A. DEAN AND P. E. H. JONES \\ Medical Research Council, Department of Experimental Medicine, University of Cambridge
}

\section{(Received 23 May 1949)}

The activities of the enzymes in serum which split acetylcholine have been investigated fairly extensively in man, both in health and disease. Enough work has also been carried out on animal sera to establish the general level of enzyme activities in the various species, and active preparations of the so-called 'pseudo' enzyme (Mendel, Mundell
\& Rudney, 1943) have been made from various tissues. It is, however, believed that no tests have hitherto been made on newborn animals, or on the colostrum and milk of their mothers. Human beings, rats, rabbits, guinea pigs, cats and dogs have been investigated in the work to be described. 